\title{
Acute middle cerebral artery thrombus
}

\author{
Siva K Talluri, Siddesh Besur
}

\section{CASE REPORT}

An 87-year-old man presented with sudden onset of right arm and leg weakness associated with difficulty in speech. His past medical history was significant for hypertension and paroxysmal atrial fibrillation. He was afebrile and hemodynamically stable. He was alert and oriented to time, place and person. Neurologic examination revealed global aphasia with right sided inattention and right sided hemiplegia with power of $1 / 5$ in the right arm and leg. Rest of the physical examination was normal. A non-contrast Computed tomography (CT) scan of head done at presentation revealed a hyperdense left middle cerebral artery suggestive of an acute thrombus (Figure 1, arrow). Repeat non-contrast CT scan of the head performed 72 hours later revealed an acute left middle cerebral artery infarct with mild mass effect on the left lateral ventricle (Figure 2, arrow).

\section{DISCUSSION}

Non-contrast CT of the head is done in the initial

Siva K Talluri ${ }^{1}$, Siddesh Besur ${ }^{2}$

Affiliations: ${ }^{1}$ Clinical assistant professor, Department of Internal Medicine, Michigan State University Internal Medicine residency program, McLaren Regional Medical Center, Flint, Michigan, USA; ${ }^{2}$ Clinical assistant professor, Department of Internal Medicine, Michigan State University Internal Medicine residency program, McLaren Regional Medical Center, Flint, Michigan, USA. Corresponding Author: Siva K Talluri MD FACP, $401 \mathrm{~S}$. Ballenger Hwy, Suite 450, Flint, MI 48532; Ph: 001-810342-5805; Fax: 001- 810-342-5810; Email: talluri1@msu.edu

Received: 10 April 2011

Accepted: 23 August 2011

Published: 01 October 2011 evaluation of patients with stroke like symptoms to exclude intracerebral hemorrhage. An intracerebral infarct may not be visible for 24 hours after the onset of stroke.The hyperdense middle cerebral artery on non-contrast head CT suggests intra-arterial clot in the presence of clinical findings suggestive of stroke. It is most useful and earliest radiological signs of ischemic stroke [1]. It is specific (specificity 100\%) [2] but less sensitive (sensitivity 5-50\%) $[1,3]$ and correlates with middle cerebral artery occlusion [3]. Though highly specific, hyperdense middle cerebral artery sign can also be seen in patients with vascular calcification and elevated hematocrit [4]. The other early signs seen in middle cerebral artery occlusion are hypodensity of brain parenchyma and cerebral edema with sulcal

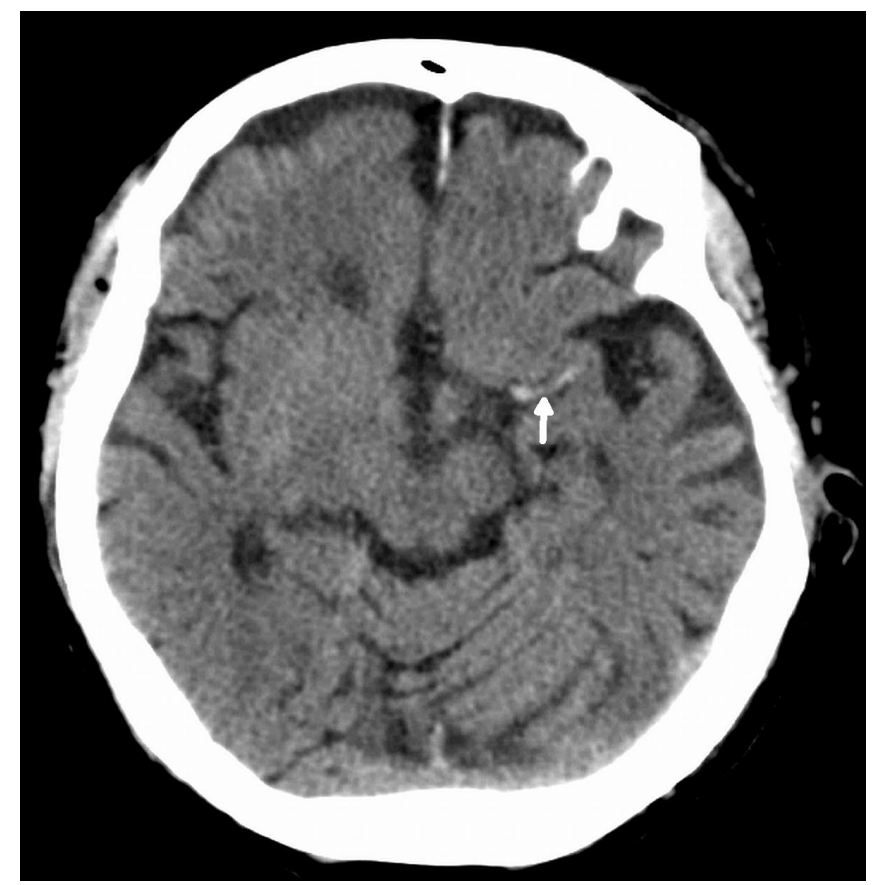

Figure 1: A computed tomography (CT) scan of the head showing hyper dense left middle cerebral artery suggestive of a thrombus (arrow). 


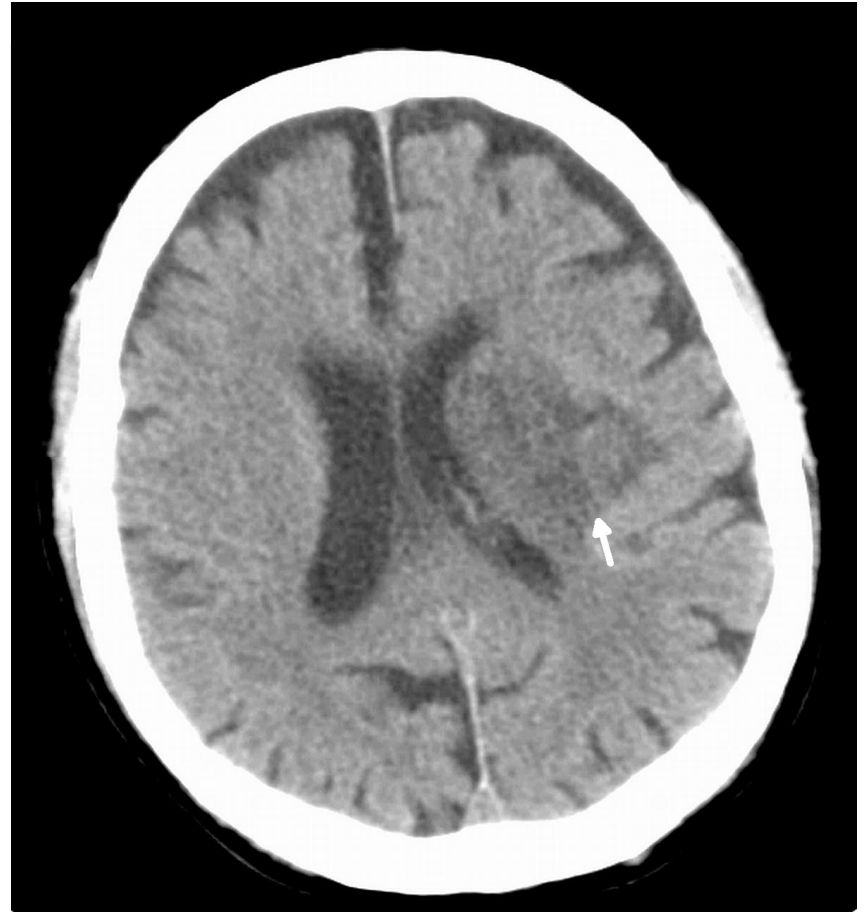

Figure 2: Repeat CT scan of the head performed after 72 hours showing an acute left middle cerebral artery infarct with mild mass effect on the left lateral ventricle (arrow).

effacement [5]. It predicts neurologic deterioration and indicates poor prognosis [6]. Hyperdense middle cerebral artery sign disappeared on a repeat CT scan 22-36 hours after thrombolysis in $48 \%$ of the patients. The disappearance of the sign indicates vessel recanalization and better prognosis [7].

\section{CONCLUSION}

The hyper dense artery sign on non-contrast CT scan of the head is one of the earliest signs of intraarterial clot and stroke in the presence of clinical findings.

$* * * * * * * * *$

Talluri SK, Besur S. Acute middle cerebral artery thrombus. International Journal of Case Reports and Images 2011;2(10):23-24.

$$
* * * * * * * * *
$$

doi:10.5348/ijcri-2011-10-62-CI-6 conception and design, Acquisition of data, Analysis and interpretation of data, Drafting the article, Revising it critically for important intellectual content, Final approval of the version to be published

Siddesh Besur - Substantial contributions to conception and design, Acquisition of data, Analysis and interpretation of data, Drafting the article, Revising it critically for important intellectual content, Final approval of the version to be published

\section{Guarantor}

The corresponding author is the guarantor of submission.

\section{Conflict of Interest}

The authors declare no conflict of interests.

\section{Copyright}

(C) Siva K Talluri et al. 2011; This article is distributed under the terms of Creative Commons attribution 3.0 License which permits unrestricted use, distribution and reproduction in any means provided the original authors and original publisher are properly credited. (Please see www.ijcasereportsandimages.com /copyright-policy.php for more information.)

\section{REFERENCES}

1. Mullins ME. The hyperdense cerebral artery sign on head CT scan. Semin Ultrasound CT MR. 2005 Dec;26(6):394-403.

2. Leys D, Pruvo JP, Godefroy O, et al. Prevalence and significance of hyperdense middle cerebral artery in acute stroke. Stroke. 1992 Mar;23(3):317-24.

3. Garg N, Eshkar N, Tanenbaum L, et al. Computed tomography angiographic correlates of early computed tomography signs in acute ischemic stroke. J Neuroimaging. 2004 Jul;14(3):242-5.

4. Koo CK, Teasdale E, Muir KW. What Constitutes a True Hyperdense Middle Cerebral Artery Sign? Cerebrovasc Dis. 200o Nov-Dec;10(6):419-23.

5. Von Kummer R, Meyding-Lamadé U, Forsting M, et al. Sensitivity and prognostic value of early CT in occlusion of the middle cerebral artery trunk. AJNR Am J Neuroradiol. 1994 Jan;15(1):9-15.

6. Manno EM, Nichols DA, Fulgham JR, et al. Computed tomographic determinants of neurologic deterioration in patients with large middle cerebral artery infarctions. Mayo Clin Proc. 2003 Feb;78(2):156-160.

7. Kharitonova $\mathrm{T}$, Thorén $\mathrm{M}$, Ahmed $\mathrm{N}$, et al. Disappearing hyperdense middle cerebral artery sign in ischaemic stroke patients treated with intravenous thrombolysis: clinical course and prognostic significance. J Neurol Neurosurg Psychiatry. 2009 Mar;8o(3):273-8.

\section{Author Contributions}

Siva K Talluri - Substantial contributions to 